\title{
(Nova) promoção da saúde: configurações no debate do serviço social
}

\section{(New) health promotion: settings in the debate of social work}

\author{
Kathleen Elane Leal Vasconcelos* \\ Valdilene Pereira Viana Schmaller ${ }^{* *}$
}

\begin{abstract}
Resumo: Odebate sobre a Promoção da Saúde (PS)vem influenciando a política sanitária de vários países, configurando um movimento denominado de Nova Promoção da Saúde (NPS). Por vezes,suas proposições são confundidas com os princípios da Reforma Sanitária Brasileira, porém há dissonâncias entre tais movimentos. Esse artigo objetivaanalisar as tendências da PS e da NPS no debate do Serviço Social. A pesquisa,bibliográfica,analisaas produções da área sobre a saúde, ancorando-se na análise de conteúdona interpretação/análisedos dados. O estudo apontaa invisibilidade da PS/NPS no Serviço Social, assim como fragilidades na discussão, o que revela a necessidade de aprofundamento teórico sobre o mesmo.
\end{abstract}

Palavras-chave: Promoção da Saúde. Reforma Sanitária Brasileira. Serviço Social.

\begin{abstract}
The debate on Health Promotion (HP) is influencing health policy in various countries, setting up a movement called New Health Promotion (NHP). Sometimes its propositions are confused with the principles of Brazilian Health Reform; however there are dissonances between such movements. This article aims to analyze the trends in HP and NHP in professional Social Work debate. The research bibliography analyzes the production area on health, anchoring in the content analysis en the interpretation/data analysis. The study highights the invisibility of HP/NHP in Social Work as well as weaknesses in the discussion, which reveals the need for theoretical development on it.
\end{abstract}

Keywords: Health Promotion. Health Reform Movement.Social Work

Recebido em: 11/11/2011. Aceito em: 20/11/2012.

\footnotetext{
"Possui graduação em Serviço Social pela Universidade Federal da Paraíba, mestrado em Sociologia pela Universidade Federal da Paraíba, doutorado pela Universidade Federal da Pernambuco. É professora da Universidade Federal da Paraíba. Trabalha no EXTRAMUROS - Revista de Extensão da UNIVASF. E-mail: leal.kathleen@gmail.com

"* Mestre em Serviço Social. Doutora em Serviço Social pela Universidade Federal de Pernambuco. Professora Associada da Universidade Federal de Pernambuco. Professora do quadro permanente do Programa de Pós-Graduação em Serviço Social da Universidade Federal de Pernambuco. Pesquisadora do Núcleo de Saúde Pública e Desenvolvimento Social da Universidade Federal de Pernambuco. Tutora do Programa de Residência Multiprofissional em Saúde da Família da Universidade Federal de Pernambuco. Tutora do PET Conexões de Saberes. E-mail: valdileneviana@uol.com.br
} 


\section{Introdução}

Nos últimos anos, o debate em torno da Promoção da Saúde (PS) tem assumido visibilidade nos meios de comunicação, nas diversas profissões sanitárias, na produção acadêmica e nas políticas de saúde de distintos países. Tal processo é expressão de um movimento internacional, denominado de Nova Promoção da Saúde ${ }^{1}$ (NPS), que emergiu a partir de meados dos anos 1970, sob os auspícios da Organização Mundial de Saúde (OMS).

A NPS questiona o modelo hegemônico de atenção à saúde, o biomédico, caracterizado, segundo Mendes (1996), pela ênfase no individualismo; pelo biologismo; pelo foco na especialização médica; pela ênfase na tecnificação do ato médico e pelo curativismo. De acordo com Teixeira (1989), em lugar de responder às reais necessidades de saúde da população, tal modelo possui íntimas relações com as necessidades de reprodução ampliada do capital que incidem ou se realizam através do setor saúde.

ANPS defende a importância de superação de tal racionalidade, apregoando ideias como a concepção holística de saúde, a importância dos Determinantes Sociais da Saúde (DSS), a relevância da intersetorialidade, da participação comunitária, do direito à saúde, da equidade, da sustentabilidade, entre outras.

Não obstante sua aparência progressista, é fundamental atentar que existem distintas concepções em torno da Promoção da Saúde, que estão relacionadas às vertentes político-ideológicas as quais seus proponentes têm se filiado, expressando as concepções do processo saúde-doença que orientam suas práticas (WESTPHAL, 2006). Carvalho (2004) considera o caráter ambíguo das premissas e estratégias da NPS, visto que seus preceitos se encontram no centro de um complexo e contraditório enredo e correm o risco de se pautar apenas numa abordagem voltada para os "estilos de vida", funcional ao discurso de redução do papel do Estado no que se refere aos direitos sociais. Em síntese, embora questione o modelo biomédico ${ }^{2}$, a NPS

\footnotetext{
${ }^{1}$ Mais adiante será explicitado o significado da adjetivação do termo.

${ }^{2}$ Cabe registrar que a configuração do movimento de NPS tem
}

constitui um verdadeiro caleidoscópio, possuindo contradições que correspondem a distintos interesses (CZERESNIA, 2003) e expressam tensões políticas e teóricas.

As polissemias dos princípios da NPS, contudo, nem sempre são percebidas, do que resulta que algumas vezes suas proposições são tomadas como sinônimos dos princípios da Reforma Sanitária Brasileira ou do Sistema Único de Saúde (SUS). Além disso, a legislação nacional, desde o início da década de 2000, está repleta de referências ao termo e adota a promoção da saúde como uma estratégia importante para o SUS, especialmente no âmbito da Estratégia Saúde da Família (ESF). No entanto, ainda que existam algumas aproximações entre o movimento internacional da NPS e a RSB, há fortes dissonâncias entre os dois movimentos, como se demonstrará a seguir.

No Serviço Social, o termo PS é recorrente nos discursos e textos relacionados à saúde. Além disso, assistentes sociais vêm se envolvendo no planejamento, execução e avaliação de projetos/programas de promoção da saúde ou se inserindo em espaços ocupacionais nos quais a NPS aparece como uma das diretrizes do trabalho (VASCONCELOS, 2013).

$\mathrm{O}$ artigo em tela objetiva analisar as tendências da PS e da NPS no debate profissional do Serviço Social,apresentando alguns resultados de uma tese de doutorado sobre o tema.

O citado estudo, descritivo e analítico, adotou a abordagem qualitativa. No desenho metodológico, utilizou a pesquisa bibliográfica.A partir de aproximações sucessivas ao objeto de estudo nas produções nacionais, dois importantes canais de divulgação da produção da área do Serviço Social foram delimitados como fontesde pesquisa: os Anaisdos Congressos Brasileiros de Assistentes Sociais ${ }^{3}$ (CBAS) e os 15 periódicos

\footnotetext{
claras vinculações com outros movimentos que colocam em questão o modelo biomédico, como a Atenção Primária de Saúde (APS), as Cidades/Municípios Saudáveis e do Desenvolvimento Sustentável (FERREIRA; BUSS, 2002), assim como as discussões em torno do "Envelhecimento Ativo" ou "Envelhecimento Saudável". Apesar de estarem estreitamente relacionados, tais movimentos muitas vezes são percebidos como se fossem processos isolados.

${ }^{3}$ É importante esclarecer que a ideia de incluir os anais de tal
evento no estudo, em lugar dos Encontros Nacionais de Pesqui-
sadores de Serviço Social (ENPESS), por exemplo, adveio do
} Emancipação, Ponta Grossa, 14(1): 129-146, 2014. Disponível em <http://www.revistas2.uepg.br/index.php/emancipacao> 
nacionais Qualis A e $\mathrm{B}^{4}$ relacionados diretamente ao Serviço Social, com base na classificação exposta em CAPES (2012). O recorte temporal adotado foi o de artigos publicados após a Política Nacional de Promoção da Saúde (PNPS), ocorridaem2006, até o ano de $2012^{5}$.

Com o objetivo de analisar a produção do Serviço Social sobre a saúde, foram estabelecidos dois critérios para a escolha dos artigos: 1) os que tivessem o termo "promoção da saúde" no título e descritores; 2) os que se voltassem para a discussão do Serviço Social nos diversos espaços ocupacionais da política de saúde. Com base em tais critérios, obteve-se 112 (cento e doze) artigos, sendo que destes setenta e três (73) são dos Anais dos CBAS(de 2007 e de 2010), e trinta e nove (39) de periódicos.

É importante mencionar que, para coleta dos dados, adotou-se um roteiro prévio de leitura, conforme indicação de Lima e Mioto (2007). Os textos analisados foram agrupados em alguns eixos temáticos ${ }^{6}$. Para análise dos dados, adotou-se a Análise de Conteúdo, seguindo as indicações de Bardin (1977)acerca das três etapas ${ }^{7}$ da técnica.

fato de que, nos CBAS, tanto há apresentação de resultados de pesquisas acadêmicas, quanto sistematização/socialização de experiências de trabalho de assistentes sociais vinculados(as) aos serviços de saúde, o que nos possibilita uma maior amplitude no acesso ao debate profissional.

${ }^{4}$ Analisou-se um total de 15 periódicos Qualis,indexados e disponíveis na Web: Argumentum, Em Pauta, Emancipação (UEPG), Katálysis, Libertas, Praia Vermelha, Revista de Políticas Públicas, Ser Social, Serviço Social e Realidade, Serviço Social e Saúde, Serviço Social e Sociedade, Serviço social em Revista, Sociedade em Debate, Temporalis.

${ }^{5} \mathrm{O}$ recorte temporal utilizado, portanto, foram os textos publicados entre janeiro de 2006 a abril de 2012 (considerando as atualizações disponíveis até o dia 15/04, quando foi encerrada a coleta de dados).

${ }^{6}$ Foram definidos 03 eixos temáticos, a saber: 1) Promoção da saúde - textos que contivessem discussões sobre PS, independentemente da relação com o Serviço Social; 2) textos gerais sobre Serviço Social e Saúde - artigos que não estivessem necessariamente relacionados a um espaço ocupacional específico, mas que tratassem da profissão ou do exercício profissional na saúde; 3 ) redes de atenção à saúde e a inserção de assistentes sociais, agrupados nas seguintes subáreas: 3.1 . Rede de atenção primária (RAPS); 3.2. Redes secundária e terciária (RST); 3.3. Saúde mental (SM); 3.4. Saúde do trabalhador (ST); 3.5. Saúde suplementar (SS).

${ }^{7}$ A primeira foi a pré-análise, que constituiu no momento da organização das informações. A segunda incidiu na análise do ma-
Para apresentar os resultados da pesquisa, este artigo empreende uma breve análise sobre a história e os princípios da NPSe sobre as críticas realizadas a esta; situa o significado da RSB e suas aproximações e distanciamentos da NPS, contextualizando em seguida a influência do citado movimento internacional no SUS; reflete sobre as configurações das discussões acerca da PS/NPS no debate do Serviço Social, apresentando alguns resultados de uma pesquisa de doutorado sobre o tema. Por fim são traçadas algumas considerações sobre essas concepções no debate do Serviço social.

\section{Promoção da saúde: raízes históricas}

A priori, gostaríamos de destacar o significado etimológico do termo "promoção" no sentido com que é usado no debate sanitário: impelir para frente; aumentar; fazer avançar; fomentar (FARIA, 1967).

Segundo Wetsphal (2006), na história da humanidade, sempre houve preocupações com a promoção da saúde do ser humano, como pode ser percebido em práticas higiênicas de civilizações passadas. Contudo, enquanto movimento, esse matiz sanitário se delineia em na década de 1970 , no contexto de críticas ao modelo hegemônico de atenção à saúde, que adquiriu conotações mais firmes no final da década citada.

Cumpre situar que o termo Promoção da Saúde foi usado pioneiramente em 1945, pelo historiador médico canadense Henry Sigerist ao definir para a Medicina quatro tarefas essenciais: a promoção de saúde, a prevenção de doenças, o tratamento dos doentes e a reabilitação (WESTPHAL, 2006). Para ele, o conceito de PS assumia um sentido amplo, que remetia à Medicina Social do século XIX: "la salud se promueve proporcionando condiciones de vida decentes, buenas condiciones de trabajo, educación, cultura física y descanso" (SIGERIST apud TERRIS,

terial, abrangendo a codificação e a categorização dos dados Ressalta-se que, durante o processo de análise textual, o material coletado foi agrupado nos eixos temáticos acima mencionados, definidos e relacionado aos espaços ocupacionais. O passo seguinte foi examinar as informações encontradas para poder analisá-las a partir do esquema de analítico da pesquisa qualitativa, ou seja, apreender as abordagens subjacentes de PS/NPS preexistentes, buscando pistas para subsidiar a etapa seguinte. A terceira fase se referiu ao tratamento dos resultados, à inferência e à interpretação dos dados encontrados. 
1992, p.38). Visando alcançar tal objetivo, o pioneiro apregoou a necessidade de esforços coordenados dos políticos, setores trabalhista e industrial, educadores e médicos, no sentido de gerar saúde. Percebe-se, então, o emprego do conceito em um sentido relativamente amplo.

Na década de1960, Leavell e Clark (1977) lançam mão da expressão em suas elaborações acerca da Medicina Preventiva ${ }^{8}$. Segundos tais autores, a promoção da saúde envolve ações que objetivam ampliar a saúde e o bem-estar gerais (e não estão voltadas para uma determinada enfermidade ou desordem) e estão situadas na primeira fase da prevenção (primária). Assim sendo, a PS se configuraria como um nível de atenção da medicina preventiva (BUSS, 2002).

Segundo Westphal (2006), o modelo de Leavell e Clark pode ser considerado um avanço no contexto de hegemonia do modelo biomédico, já que chama a atenção das/os profissionais de saúde para importância da Prevenção de Doenças, em especial quanto às ações sobre o ambiente e sobre os estilos de vida. No entanto, prossegue a analista mencionada, a proposta defendida pelos autores não apreende os efeitos das condições de vida e trabalho nos níveis de saúde das populações.

É relevante frisar que as propostas em torno da Promoção da Saúde, retomadas com ênfase na década de 1970, não surgem no etéreo, mas num contexto fortemente marcado pela crise do capitalismo e pela ascensão de propostas neoliberais. É também um cenário marcado por reivindicações de movimentos sociais que, em diversas partes do globo, lutavam por direitos sociais, entre eles o direito à saúde; por um processo de mudanças no perfil de morbimortalidade da população de diversos países, principalmente os centrais, que colocam em evidência o papel das doenças crônico-degenerativas; por constatações da falta de efetividade de um sistema de

\footnotetext{
8 "É importante mencionar que, entre as décadas de 1930 e 1940, emerge, nos EUA, o movimento de medicina preventiva que, partindo da história natural das doenças e tendo como disciplinas básicas para a intervenção a epidemiologia e a clínica, propunha uma série de medidas preventivas que ampliariam uma lacuna da prática médica: a atitude preventiva e social (PAIM, 2006). 'Apontava para a possibilidade de redefinição das responsabilidades médicas através de mudanças na educação, mantendo a organização de serviços de saúde na perspectiva da medicina liberal'" (VASCONCELOS, SCHMALLER, 2011, p. 4).
}

saúde direcionado ao atendimento das situações agudas de adoecimento. Todo esse processo culminou em diversas críticas ao modelo biomédico (VASCONCELOS; SCHMALLER, 2011).

É com o documento "ANew Perspective on the Health of Canadians" (conhecido como Informe Lalonde), publicado em 1974, de autoria do então assessor do ministro da saúde do Canadá, Marc Lalonde (CARVALHO, 2005), que o uso do termo promoção da saúde se consolida. A partir da constatação de que estavam sendo gastas grandes somas de dinheiro para tratar doenças que poderiam ter sido prevenidas (LALONDE, 1996), este autor propõe a priorização, por parte dos gestores da política de saúde, de medidas não apenas voltadas para os serviços de saúde e para o atendimento curativo, mas direcionadas para a prevenção e para programas educativos focados em mudanças comportamentais e de estilos de vida.

Num contexto em que as doenças crônicodegenerativas assumiam um papel cada vez mais relevante nos indicadores de morbimortalidade, as ideias do autor se espraiaram por todo o mundo, sob a regência da OMS, impregnando práticas de promoção de saúde com foco na modificação de hábitos, estilos de vida e comportamentos individuais não saudáveis, entre os quais o tabagismo, a obesidade, questões relacionadas à sexualidade e ao abuso de substâncias psicoativas. Carvalho (2004) denomina tal vertente de Promoção da Saúde behaviorista.

Westphal (2007) indica, porém, que o marco inicial da NPS não foi o Relatório Lalonde, mas a Conferência Internacional de Cuidados Primários, realizada em Alma Ata, em 1978, pela OMS. No evento, a saúde é entendida como direito humano fundamental e se chama a atenção para seus determinantes sociais, sendo feita uma proclamação para a ação de todos os governos, profissionais de saúde e de desenvolvimento e a comunidade mundial no sentido de proteger e promover a saúde de todos os povos (OMS, 1978).

Segundo Carvalho (2005), em linha de continuidade com Alma-Ata, ocorre a atualização do Movimento de Promoção da Saúde ${ }^{9}$,

\footnotetext{
9 Agora denominada de "Nova" Promoção da Saúde ou de Vertente Socioambiental da Promoção da Saúde, como aponta
} 
com a finalidade de superar as fragilidades do projeto de PS behaviorista. É neste clima que ocorre a I Conferência Internacional sobre Promoção da Saúde, em 1986, não por acaso em Ottawa, Canadá. Aí a NPS aparece como uma forma nova de reativar a necessidade de ações intersetoriais e as intervenções no solo político visando melhoria das condições de saúde no planeta (RESTREPO, 2001).

Na Carta de Ottawa, são considerados como condições e recursos fundamentais para a saúde: paz, habitação, educação, alimentação, renda, ecossistema estável, recursos sustentáveis, justiça social e equidade (BRASIL, 2002). No documento, a NPS é conceituada como

O processo de capacitação da comunidade para atuar na melhoria de sua qualidade de vida e saúde, incluindo uma maior participação no controle deste processo. Para atingir um estado de completo bem-estar físico, mental e social os indivíduos e grupos devem saber identificar aspirações, satisfazer necessidades e modificar favoravelmente o meio ambiente. A saúde deve ser vista como um recurso para a vida, e não como objetivo de viver. Nesse sentido, a saúde é um conceito positivo, que enfatiza os recursos sociais e pessoais, bem como as capacidades físicas. Assim, a promoção da saúde não é responsabilidade exclusiva do setor saúde, e vai para além de um estilo de vida saudável, na direção de um bem-estar global (BRASIL, 2002, p.20).

A mencionada Conferência define cinco campos da promoção da saúde (BRASIL, 2002): a) políticas públicas saudáveis; b) criação de ambientes favoráveis; c) reforço da ação comunitária; d) desenvolvimento de habilidades pessoais; e) reorientação dos serviços de saúde ${ }^{10}$.

Após tal Conferência foram realizadas pela OMS e suas regionais outros eventos multinacionais, que contaram com a presença de representantes dos mais distintos países e cumprem importante papel no desenvolvimento/ amadurecimento do conceito de NPS.

Westphal (2006). Tal adjetivação busca superar a vertente behaviorista associada à promoção da saúde (CARVALHO, 2004), que se foca nos estilos de vidas individuais, bem como expressar a incorporação do debate ambiental.

10 Para maiores informações sobre o significado de cada um deles, cf Wetsphal (2006).
A partir de tais eventos, são considerados princípios da NPS: a) a concepção "holística" de saúde; b) a equidade; c) a intersetorialidade; d) o empowerment; e) a participação social; f) as ações multi-estratégicas; g) a sustentabilidade (OMS, 1998).

Ainda que fuja ao escopo desse artigo uma incursão analítica mais aprofundada em tais princípios, cumpre-nos fazer algumas reflexões que consideramos ser centrais em relação aos mesmos ${ }^{11}$, conforme veremos a seguir.

\section{Nova Promoção da Saúde: algumas anotações críticas}

Ainda que de forma bastante sumária, traçaremos a seguir algumas considerações fundamentais para problematizar os princípios da NPS.No que se refere à concepção holística de saúde, esta é uma compreensão extremamente importante para uma intervenção mais ampla no processo saúde-doença, bem como para o repensar da política sanitária. No entanto, alguns autores vêm chamando a atenção para a necessidade de cuidados no uso desse conceito. Segundo Czeresnia (2003, p.11), quando se concebe a saúde "em seu significado pleno, está-se lidando com algo tão amplo como a própria noção de vida".

Quanto ao princípio da equidade, ainda que as políticas nesta direção possam contribuir para o alcance da igualdade, este é um debate complexo, envolvendo elucubrações referentes à justiça social, temática que certamente demanda estudos aprofundados, especialmente porque, no bojo da busca pela racionalização dos gastos públicos, "a eficiência e a equidade aparecem como elementos centrais, traduzidos na focalização dos mais pobres como alvo prioritário das ações governamentais" (SENNA, 2002, p.204).

É importante situar que o movimento da NPS, ainda que se coloque contrário às iniquidades em saúde, não aborda a complexidade das expressões da questão social, que estão indissociavelmente vinculadas ao modelo de desenvolvimento sócio econômico adotado

\footnotetext{
${ }^{11}$ A conceituação de NPS da Conferência, além das considerações que teceremos a seguir, necessita de uma cuidadosa análise, por assumir conceitos permeados de contradições, como o de "comunidade", "qualidade de vida", "bem-estar global".
} 
(CEBES, 2009). Exemplo disso é que, segundo Carvalho (2004), em determinadas vertentes da NPS, temas como conflito de classes e a relação capitalismo e saúde tem uma presença quase sempre marginal. Assim, embora denuncie a iniquidade em saúde ${ }^{12}$, a NPS não se debruça sobre as relações geradoras de tais situações, que estão intimamente associadas ao capitalismo em sua fase financeira, predatória e parasitária.

Deste modo, ainda que adote uma perspectiva "socioambiental", no discurso da NPS tem havido um deslocamento da centralidade do direito à saúde em direção a mudanças de estilo de vida individual. Nesse bojo, o adoecimento passa a ser percebido, por vezes, como consequência de atitudes individuais, da falta de envolvimento em atividades motivadoras ou da adoção de formas de consumo e estilos de vida inadequados (DEBERT, 1999). Além disso, Luz (2000) avalia que, na contemporaneidade, a saúde se tem transformado em um mandamento para todos os indivíduos. Neste âmbito, Berlinguer (1993) denuncia a possibilidade de expansão do que denomina de "salutismo" e obsessão pela saúde: a tendência da busca pela saúde ser compreendida como objetivo de vida. Neste cenário,

incentiva-se a incorporação maciça de normas para uma vida saudável: dietas, atividades físicas, serviços de estética, alimentação saudável, etc. Assim, em nome da PS, proliferam práticas excessivamente intervencionistas, coercitivas sobre a vida privada e apontando para a restrição de escolhas livres (VASCONCELOS, 2013, p.108).

Ao colocar para os sujeitos a responsabilidade por sua condição de saúde, tal perspectiva pode alimentar a tendência de enxugamento de gastos do Estado com políticas sociais.

Tal perspectiva pode ser endossada com a ênfase da NPS na intersetorialidade, proposta indubitavelmente fundamental para avançar no enfrentamento da determinação social da saúde, inclusive defendida pela RSB. Contudo, o excessivo foco na intersetorialidade e nas políticas públicas saudáveis indica a possibilidade da NPS de secundarizar a atenção à saúde em

\footnotetext{
${ }^{12}$ Sobre os conceitos iniquidade e equidade em saúde, Cf Vieira da Silva e Almeida Filho (2009); Campos (2006).
}

prol de ações exteriores aos serviços de saúde, "(...) como se a responsabilidade pelas ações promocionais somente indiretamente dissessem respeito ao campo da saúde, o que tende a respaldar o enxugamento de gastos estatais com a atenção à saúde" (VASCONCELOS; SCHMALLER, 2014, p.78). Tal compreensão respaldaria a diminuição de recursos para o setor saúde, já que abre margem para que o discurso de certos legisladores e gestores, para quem, se "tudo é saúde", os (parcos) recursos do SUS podem ser aplicados em outras áreas sociais (CAMARGO JR, 2007), secundarizando a imprescindibilidade do financiamento efetivo da política pública de saúde.

Em relação ao princípio da participação social, sabe-se que, para se construir num sistema de saúde que seja usuário-centrado e supere as práticas autoritárias que historicamente caracterizam a atenção à saúde, esse é um elemento fundamental. No entanto, a NPS corre também o risco de reeditar antigos conhecidos nossos como o discurso desenvolvimentista de "comunidade" ou "participação", ao enfatizar a resolução dos "problemas" de cada "comunidade", como se estes pudessem ser isolados, desconectados da formação sócio-histórica que os geram. Nesse sentido, Campos (2005) identifica na NPS uma fervorosa empolgação com a crença no poderio de ações comunitárias, locais e intersetoriais, como se pudessem solucionar as desigualdades sociais.

No campo da Nova Promoção da Saúde, segundo Stotz e Araújo (2004), o empowerment, distante de ser visto como meio de fortalecer a ação coletiva contra as estruturas de poder, é concebido como "(...) um método de construção de consenso que exige negociação e concertação social" (STOTZ; ARAÚJO, 2004, p.14). Ainda para os autores, os profissionais de saúde pautados na NPS, ao exercerem o papel de "empoderadores",

(...) assumem a tarefa de reatar os fragmentos de vidas que perderam sentido social e tornam-se, eles próprios, os referentes para a reconstrução dessas identidades sociais. É por isso que o empowerment, independente da intenção de politizar a promoção da saúde, pode ser visto como uma nova forma de tutela sobre a maioria da população (STOTZ; ARAÚJO, 2004, p.14). 
É relevante situar também que a disseminação da ideologia da promoção da saúde tende a gerar um novo padrão de consumo, do qual resulta uma importante alimentação do "mercado da saúde" - o dos produtos "saudáveis" - que constitui atualmente um dos sustentáculos fundamentais da acumulação capitalista, não arrefecendo nem mesmo em momento de crise econômica (CEBES, 2009).

Não podemos deixar de mencionar que a própria concepção de PS/NPS é palco de largas tensões: Chapela e García (2010) constatam a existência de duas grandes vertentes no debate. A primeira diz respeito às perspectivas de PS subalternizantes, que englobam a "promoção da saúde do mercado"; a PS "oficial" e outras perspectivas que adensam uma abordagem culpabilizante do indivíduo; a segunda abarca as concepções nas quais a PS é tratada na direção da emancipação.

La perspectiva dominante de promoción de la salud está centrada en la modificación de riesgos y estilos de vida a partir de lo cual ignora los determinantes sociales de la salud, desvincula la política sanitaria de la económica y se suma acríticamente a la tendencia a la mercantilización y privatización de los servicios de salud. Funge como un legitimador de las desigualdades sociales al tiempo que culpabiliza e individualiza la salud, ignorando los procesos colectivos. Frente a ello, es posible ubicar una perspectiva emergente de promoción de la salud que denuncia la desigualdad social y retoma los determinantes sociales de la salud dando centralidad a la noción de derechos sociales; vincula la política sanitaria e la económica; cuestiona la mercantilización de la promoción de la salud; propicia procesos colectivos que implican la decisión de los sujetos al tiempo que promueve procesos de exigibilidad/ emancipación (GARCIA, 2010, p.89).

Diante da complexidade que envolve o debate da NPS, não é de surpreender que nos deparemos com trabalhos na perspectiva da PS/ NPS heterogêneos: há tanto produções teóricas, legislações e experiências com marcas subalternizantes quanto com perspectivas progressistas.

Como se pode perceber do exposto, os princípios da NPS possuem caráter ambíguo (CARVALHO, 2004), visto que seus preceitos se encontram no centro de um complexo e contraditório e correm o risco de se pautar apenas numa abordagem voltada para os "estilos de vida", funcional ao discurso de redução do papel do Estado no que se refere aos direitos sociais, mas também possui potencialidades de contribuir efetivamente para a mudança do modelo de atenção à saúde, se sua adoção for realizada sob o ideário da RSB. A partir de tais considerações, voltar-nos-emos para o debate sobre a NPS no Brasil e suas relações com a RSB.

\section{O Debate entre a Reforma Sanitária Brasileirae a Nova Promoção da Saúde}

Herdeiro e coadjuvante da "Medicina Social" Latino Americana, o movimento em torno da Reforma Sanitária Brasileira se articula a partir do final dos anos 1970, envolvendo profissionais de saúde, usuários e movimentos sociais.

Embora seja um movimento heterogêneo, deve muito de suas reflexões ao referencial marxista, especialmente através da adoção da perspectiva da determinação social do processo saúde/doença, através da qual busca apreender as "determinações contraditórias e simultâneas decorrentes de necessidades do capital e do trabalho" (TEIXEIRA, 1989, p. 18) e suas relações com as condições de vida e de saúde das populações.

Para compreensão do processo da RSB, Teixeira (2009) indica algumas de suas hipóteses explicativas, das quais destacamos a adoção de uma concepção ampliada de saúde como resultante das formas de organização social da produção, mas também fruto das lutas populares cotidianas, ambas atuando na conformação de sua concretização histórica e singular; a luta pela democracia na sociedade brasileira, na política e no modelo de atenção à saúde; a consideração das classes populares como sujeitos políticos; a busca da generalização da consciência sanitária; a reivindicação da sustentabilidade financeira necessária à construção de um sistema amplo de proteção social; entre outros.

Paim (2008a) afirma que a Reforma Sanitária Brasileira (RSB) não se referia apenas a mudanças na política de saúde, mas a uma totalidade de mudanças, que abrange diversas reformas: "social", do Estado, da sociedade e da cultura, intelectual e moral. 
A Carta Magna de 1988 incorporou algumas das demandas do Movimento em tela e considera a Saúde como um dos tripés da seguridade social, ao lado das políticas de previdência e assistência social. A saúde é concebida como dever do Estado e direito de cidadania.

Vale registrar que, segundo Paim (2008a), a RSB não se constitui apenas do movimento social que a propulsou nem meramente uma política social e de saúde, portanto, não se reduz ao SUS (ainda que este expresse algumas de suas dimensões setorial, institucional e administrativa). Desta forma, contrariando a ideia de que esteve circunscrito às décadas de $1970 \mathrm{e}$ 1980 ou que se resuma à luta pela criação do SUS, a RSB não foi algo limitado a um delimitado período histórico, mas prossegue enquanto horizonte dos sujeitos comprometidos com a saúde enquanto direito. Na avaliação do autor, a partir de 2005 vem ocorrendo um processo de rearticulação de movimentos acadêmicos e movimentos profissionais na defesa da Reforma Sanitária ${ }^{13}$.

Não obstante, como indicam Bravo e Correia (2012), algumas das questões centrais postas pela RSB (anteriormente referidas) não mais estão subjacentes às reivindicações de algumas das entidades de referência nos anos 1970 e 1980 ou de autores que foram fundamentais na luta pela Reforma no período citado, como a determinação social do processo saúde e doença, a luta contra a privatização e a defesa intransigente da saúde pública. Neste contexto, alguns/as militantes vêm buscando retomar as bandeiras acima destacadas, a exemplo da articulação em torno de "Fóruns em Defesa do SUS e contra as privatizações".

No que se refere à discussão sobre a NPS no Brasil, de acordo com Campos (2006a), este é um tema que provoca controvérsias: apesar de serem coetâneos e dos visíveis pontos de intersecção entre os dois movimentos no que se refere aos questionamentos ao modelo biomédico, aconteceu, na década de 1980, uma

\footnotetext{
${ }^{13} \mathrm{O}$ analista afirma que tal renovação teria como vanguarda o Centro Brasileiro de Estudos de Saúde (CEBES) e aglutina entidades como a Associação Brasileira de Pós-Graduação em Saúde Coletiva (ABRASCO), a Associação Brasileira de Economia da Saúde (ABRES), a Rede Unida e a Associação Nacional do Ministério Público de Defesa da Saúde (AMPASA) e a Sociedade Brasileira de Medicina de Família e Comunidade (SBMFC).
}

postura de reserva política das/os defensores/ as da RSB quanto às proposições da NPS (VASCONCELOS; SCHMALLER, 2014).

Segundo Pasche e Hennington (2006), a RSB tem como uma de suas categorias mais caras a perspectiva da totalidade, herança marxista, angulação esta responsável por boa parte de sua criticidade em relação à NPS. Nesse sentido, a RSB tem como concepção basilar a determinação social da saúde ${ }^{14}$, que se contrapõe à vertente da NPS que normatiza estilos de vida e culpabiliza indivíduos, priorizando o enfoque nas mudanças dos comportamentos individuais (VASCONCELOS, 2013).

Pasche e Hennington (2006)mostram que a RSB, nos anos 1980, com sua preocupação com a reforma do sistema de saúde como um todo, contrapunha-se à tradição dos organismos internacionais, de adoção da APS e da NPS "sem, muitas vezes, se propor mudanças na dinâmica da organização dos modos de produção de saúde, hegemonizados, como no Brasil, por serviços e práticas direcionados para a cura e reabilitação, sustentadas na lógica do mercado privado" (PASCHE; HENNINGTON, 2006, p.20).

De acordo com os analistas mencionados, outra peculiaridade do movimento tupiniquim é a compreensão da saúde como dever do Estado e direito de cidadania, não sendo suficientes meras orientações de governo, conforme propunha a NPS, "mas se exigia dele o cumprimento de orientações gerais inscritas na formalidade do Estado de Direito" (PASCHE; HENNINGTON, 2006, p.21).

Concomitantemente, considerava-se a NPS como um conjunto de propostas elaboradas em países centrais, com realidade socioeconômica bastante distinta do quadro nacional e com problemas sanitários também diferentes, como podemos perceber na reflexão abaixo:

\footnotetext{
14 "É importante situar que a determinação social da saúde tem suas bases na perspectiva marxista; já os DSS, de acordo com Tambellini, Schutz (2009) e CEBES (2009), tem como o modelo da epidemiologia tradicional, no qual estes aparecem unicamente na qualidade de fatores causais de morbidade e mortalidade, sendo um conceito puramente empírico. Não existiria aí nenhum tipo de teoria da sociedade de caráter crítico ou ao menos explicativo, conforme alerta o CEBES (2009). Nesse sentido, de acordo com o documento citado, o problemático da concepção do DSS é acreditar que a atuação nos 'fatores de risco' pode minimizar a determinação social, sem que se transformem efetivamente as condições sociais" (VASCONCELOS; SCHMALLER, 2014, p. 05).
} 
Em contraposição a esta perspectiva, devemos supor que a promoção da saúde nos países periféricos depende, em grande medida, de políticas universalistas em áreas como trabalho, educação, saneamento básico e preservação ambiental. Essas, por sua vez, estão vinculadas à política econômica (STOTZ, ARAÚJO, 2004, p.14).

Buss e Carvalho (2008) assinalam que, na América Latina, foi cunhada a expressão promoção da saúde "radical" para indicar que o movimento de NPS precisa estar articulado à perspectiva da mudança social.

Em nossa concepção, o termo promoção da saúde não foi devidamente trabalhado pelos defensores da Reforma Sanitária nos anos 1980, apesar de incorporado textualmente na Constituição Federal de 1988 e ser utilizado em diversas publicações da área. É a partir da década de 1990, contexto em que a influência do marxismo na Saúde Coletiva arrefece, que passa a acontecer uma crescente incorporação da NPS em território tupiniquim, geralmente de forma acrítica.

Na política nacional, é possível observar a influência do movimento internacional em diversas iniciativas do Ministério da Saúde, como veremos a seguir.

\section{O Sistema Único de Saúde e a Nova Promoção da Saúde}

A partir de meados dos anos 1990,vem ocorrendo a disseminação do ideário da NPS no cenário nacional e nos anos 2000 esse processo se expande, culminando na publicação da PNPS, anteriormente referida.

Um marco pioneiro desse processo é a publicação de Mendes(1996) que,conforme observam Buss e Carvalho (2009), incorporou explicitamente a discussão da NPS e dos municípios saudáveis ${ }^{15}$.

\footnotetext{
${ }^{15}$ Pela relevância desse autor no tratamento da temática, principalmente por sua ampla divulgação em nível nacional, inclusive entre assistentes sociais, cumpre fazer algumas indicações acerca de suas ideias sobre a NPS. Mendes (1996) defende que um novo sistema de saúde, conforme previsto pelo SUS, requer a reconstrução dos fundamentos medulares do modelo de atenção, através de mudanças concomitantes e dialéticas na concepção saúde-doença (através da adoção do conceito positivo de saúde); no paradigma sanitário (via incorporação da produção social); na "prática" sanitária (através da superação da prática médica pela
}

Na política sanitária nacional, é possível observar a influência da NPS na escolha da APS (via Estratégia Saúde da Família - ESF) como "estratégia" para mudança do modelo de atenção, já em meados dos anos 1990. Além da ESF (e do Programa de Agentes Comunitários de Saúde - PACS), podem ser mencionadas também a herança da NPS no campo das práticas de Educação à Saúde (CARVALHO, 2004), em programas como o de Controle do Tabagismo, o de Controle do HIVIAIDS, o de Controle da Hipertensão e Diabetes, assim como nas discussões em torno da estruturação do sistema de vigilância da saúde no SUS (TEIXEIRA, 2006).

Cumpre indicar também que, a partir de 2006, a NPS ganha destaque na política nacional, em virtude de sua inclusão dentre as diretrizes e prioridades do Pacto pela Vida, em Defesa do SUS e de Gestão (CASTRO; MALO, 2006); da instituição da Comissão Nacional dos Determinantes Sociais da Saúde (CNDSS); e da publicação da Política Nacional de Promoção da Saúde (PNPS).

Ainda que ultrapasse o escopo de nosso trabalho analisar a PNPS, é importante fazer algumas indicações a seu respeito ${ }^{16}$. A mesma

Vigilância da Saúde - VISAU); na ordem governativa da saúde na cidade (através da construção de políticas públicas saudáveis) Para efetivação desse processo, seriam necessários dois movimentos concomitantes: o primeiro, de ordem mais geral, modificando a racionalidade governativa da cidade (MENDES, 1996) num sentido que possibilite tornar este espaço um local de produção social da saúde, via políticas públicas saudáveis; o segundo diz respeito à reorganização dos serviços de saúde. Neste âmbito, deve ser adotada a estratégia da vigilância da saúde. Esta precisa combinar, com eficácia e eficiência, três tipos de ações: a atenção curativa, a prevenção e a promoção, sendo crescente a sua ordem de importância no processo de trabalho das equipes de saúde. Nesta compreensão, a promoção da saúde abrange o desenvolvimento de ações voltadas para a melhoria da qualidade de vida da população atendida, a partir da constatação do papel protagônico dos determinantes gerais sobre as condições de saúde (MENDES, 1996). Vale ainda mencionar que, segundo este autor, a vigilância da saúde requer um trabalho interdisciplinar e possui como pilares o território, os problemas de saúde e a intersetorialidade (MENDES, 1996). Esta formulação, também incorporada por importantes analistas como Paim (1999) e Teixeira (2006), é bastante divulgada, estando presente especialmente nas publicações do Ministério da Saúde referentes à ESF, embora haja diversas outras perspectivas sobre a NPS em nível nacional.

${ }^{16}$ Em estudo sobre o processo de elaboração da PNPS, Cruz (2010) demonstra que, distante de se configurar como uma resposta às demandas da RSB, o principal impulso para sua publicação adveio da OMS, pela via do documento "Estratégia Global de alimentação saudável, atividade física e saúde" (OMS, 
tem como objetivo principal:

Promover a qualidade de vida e reduzir vulnerabilidade e riscos à saúde relacionados aos seus determinantes e condicionantes - modos de viver, condições de trabalho, habitação, ambiente, educação, lazer, cultura, acesso a bens e serviços essenciais (BRASIL, 2006, p.13).

Para tanto, o documento acima recomenda o incentivo às ações de PS em todos os níveis de atenção, com realce para a APS.

No texto da PNPS, é notável uma tensão entre a introdução da Política e o restante do documento: apesar dos amplos objetivos e da menção à NPS, as ações propostas são voltadas prioritariamente para mudanças nos estilos de vida individuais. Nesta perspectiva, a política propõe a priorização de ações voltadas para: alimentação saudável; prática corporal/ atividade física; prevenção e controle do tabagismo; redução da morbimortalidade em decorrência do uso abusivo de álcool e outras drogas; redução da morbimortalidade por acidentes de trânsito; prevenção da violência e estímulo à cultura de paz; promoção do desenvolvimento sustentável. Cruz (2010) afirma que, distintamente do que se poderia presumir, a política em foco caminha na contramão da concepção da NPS, possuindo mais claramente o enfoque preventivista de Leavell e Clark (1977).

Vale situar que, relacionadas à PNPS, são desenvolvidas algumas iniciativas, dentre as quais se destaca a publicação da Política Nacional de Práticas Integrativas e Complementares no SUS, também em 2006. Outro marco é a publicação da Portaria No 4.074/ 2010,visandoautorização de repasse financeiro para estados e municípios, através do Piso Variável de Vigilância e Promoção da Saúde (PVVPS). Em 2011, através da Portaria $n^{\circ} 719$, é criado o Programa Academia da Saúde, que, segundo o Ministério da Saúde (BRASIL, 2011a) visa contribuir para a promoção da saúde da população a partir da implantação de polos com infraestrutura, equipamentos e quadro de pessoal qualificado para a orientação de práticas corporais e atividade

2004), que requisita dos países membros o desenvolvimento de ações no sentido do enfrentamento da morbimortalidade por doenças crônico-degenerativas. física e de lazer e modos de vida saudáveis. Além disso, no mesmo ano, é elaborado o Plano de ações estratégicas para o enfrentamento de Doenças Crônicas Não Transmissíveis (DCNT) no Brasil (2011-2011) (BRASIL, 2011b).

Outro conjunto de ações oficiais no âmbito da NPS são as iniciativas da Agência Nacional de Saúde (ANS) no sentido de uma regulação indutora da saúde suplementar no país, através da elaboração de uma política que visa à qualificação da atenção à saúde, incentivando a adoção da prevenção de riscos e enfermidade e da promoção da saúde no modelo de atenção até então promovido pelas operadoras de planos privados de saúde (ANS, 2011) ${ }^{17}$.

Algumas importantes ações intersetoriais ${ }^{18}$ também vêm sendo desenvolvidas no rastro da PNPS: a implantação do Programa Saúde na Escola, em 2007, com a articulação entre os Ministérios da Saúde e da Educação; o Lançamento do Plano Nacional de Atividade Física, em 2009, via integração entre Ministérios da Saúde e do Esporte.

É importante mencionar que propostas em torno das Políticas Públicas Saudáveis também vêm sendodesenvolvidasem diversos locais do país,associadas ao movimento das Cidades/Municípios Saudáveis ${ }^{19}$. Os objetivos das Políticas Públicas Saudáveis perpassam a busca da melhoria da qualidade de vida da

\footnotetext{
17 Para maiores informações, cf.Czenesria(2003), Franco et al(2011), ANS (2011).

${ }^{18}$ Costa (2010, p.125) lembra também que são elencadas como ações de Promoção da Saúde "as políticas de combate à fome (atendimento às carências nutricionais); a aprovação do Estatuto do Desarmamento e o recolhimento de armas de fogo; o aumento dos investimentos em saneamento básico".
}

\begin{abstract}
${ }^{19}$ De acordo com Schmaller; Franco de Sá e Silva (2014), baseadas em Akermanet al (2002), as duas terminologias são utilizadas no Brasil, o que teria relação com momento de aproximação ao ideário: aqueles que se envolveram com as propostas do governo canadense, usam o termo "Cidades Saudáveis"; já que os que foram sensibilizados por entidades como a Organização PanAmericana de Saúde (OPAS), adotaram a expressão "Municípios Saudáveis". Segundo, Pasche e Hennington (2006), sob a orquestração da OMS, este último adentra à América Latina nos anos 1990, junto com o processo de descentralização e da difusão dos Sistemas Locais de Saúde (SILOS) pela Organização Panamericana de saúde (OPAS). Paim (2003) refere que a proposta foi abraçada pelo Conselho Nacional de Secretários Municipais de Saúde (CONASEMS), conforme expresso oficialmente na Carta de Fortaleza, lançada em 1995, que defende a adoção, no SUS, da NPS, da Intersetorialidade, da filosofia dos Municípios Saudáveis, bem como do ideário da "Cultura da Paz".
\end{abstract}


população, a execução de políticas públicas saudáveis, tendo a intersetorialidade como estratégia principal (PASCHE; HENNINGTON, 2006). Segundo Teixeira (2003), o projeto vem sendo incorporado por algumas administrações municipais nos últimos anos.

Vale situar que foi criado um Grupo Temático na ABRASCO intitulado "Promoção da Saúde e Desenvolvimento Local Sustentável" (PSDLIS), que inclui redes de instituições de ensino, com apoio do Ministério da Saúde (MS) e da Organização Pan-Americana de Saúde (OPAS).

Sabe-seque, apesar de todas as reivindicações e propostas da RSB, dos avanços legais e da divulgação das discussões sobre a PS/NPS, constata-se que as alterações no modelo de atenção à saúde, no Brasil, são ainda incipientes. Tal processo tem a ver com o contexto socioeconômico vivenciado no país: os direitos sociais inscritos na Constituição Federal estão sempre sendo postos em questão em nome de ajustes fiscais (débitos públicos) e monetários (combate à inflação) (DRUCK; FILGUEIRA, 2007). As políticas sociais, focalizadas, objetivam, de maneira parcial e restrita, enfrentar os estragos resultantes do neoliberalismo, definindo-se então por "ser a contraface dos superávits fiscais primários" (DRUCK; FILGUEIRA, 2007). O outro lado da moeda das políticas focalizadas corresponde ao agudizamento do processo de mercantilização das mesmas, em uma lógica na qual os direitos sociais deixam de ser referência-mestre (PEREIRA, 2009), para dar lugar ao acesso através do mercado.

No campo da saúde, na década de 2000 , especialmente durante o governo Lula, esse tensionamento se reveste de novas roupagens: segundo Soares (2010a), há menções do governo à defesa da saúde pública, porém são inseridos conteúdos inconciliáveis com o projeto da RSB; o escasso financiamento da política de saúde é tido como um fato e os conteúdos de tensão são deslocados para o nível da gestão em saúde, havendo a defesa de novas modalidades de gestão, como as polêmicas Fundações Estatais de Direito Privado, as Organizações Sociais (OS), as Organizações da Sociedade Civil de Interesse Público (OSCIP), a Empresa Brasileira de Serviços Hospitalares (EBSERH). Enfim, a saúde é tida não apenas como um campo de direito, porém como espaço econômico estratégico, como se pode perceber no Programa Mais Saúde.

É nesse solo que o SUS vem sendo tecido e, em seu interior, o modelo tradicional continua se ampliando e consolidando: a hegemonia da racionalidade biomédica se mantém em todas as esferas de atenção à saúde. Suas ideias e valores seguem predominantes e orientam a formação e o trabalho sanitário (FEUERWERKER, 2007), bem como a gestão do sistema.

Em tal contexto, Soares (2010b, p.104) nos chama atenção para a existência de uma promoção da saúde restrita no contexto da racionalidade da contrarreforma que,

(...) ao não viabilizar a efetivação de políticas públicas estruturais e universais que promovam qualidade de vida que incidam diretamente sobre os determinantes sociais, termina possibilitando que, tendencialmente, as políticas de saúde enfatizem as práticas e comportamentos saudáveis, centralizandose na responsabilização do indivíduo sobre o processo saúde-doença.

Cumpre demarcar que o debate e as propostas em torno promoção da saúde/NPS, ainda que contraditórios, podem, inclusive, contribuir para a retomada das teses centrais da RSB, conforme propostasnos anos 1980, e para a luta pela mudança do modelo de atenção à saúde hegemônico.

Nesse estudo, adotou-se a ousada acepção da PS como uma estratégia ideopolítica que considera a determinação social da saúde nos termos e princípios clássicos formulados pelo Movimento da Reforma Sanitária Brasileira, cujas mediações tem como centro a produção social da saúde. Nestes termos, a PS deve se fazer presente na gestão pública em geral (e seus esforços no sentido da intersetorialidade entre as políticas econômicas e as demais políticas sociais) e, concomitantemente, nortear os serviços sanitários em todas as redes de atenção e parametrar o trabalho dos diferentes gestores e profissionais, em suas formas de abordagem e atuação. Materializa-se através da combinação de ações e atividades que requerem necessariamente a intersetorialidade, a interdisciplinaridade, as ações multi-estratégicas e a participação popular, em sua articulação com as lutas sociais pela saúde em sentido ampliado, como direito de todos e dever do Estado. 
Tendo tais considerações como horizonte, voltar-nos-emos agora para os delineamentos das discussões sobre a PS/NPS no debate do Serviço Social.

\section{O debate sobre a (Nova) Promoção da Saúde no Serviço Social: breves considerações}

A priori é importante contextualizar que os processos relativos à implementação do SUS gestaram o redimensionamento do trabalho sanitário, inclusive do/a assistente social, assim como o alargamento dos espaços profissionais e a emersão/consolidação de novas demandas para o processo de trabalho em saúde.

Neste cenário, conforme Vasconcelos (2013), o debate profissional dos assistentes sociais sobre a saúde vem adquirindo maior densidade e amplitude. A partir dos anos 2000, percebe-se um maior envolvimento da categoria com as discussões da Saúde Coletiva (KRUGER, 2010), especialmente a partir do reconhecimento da confluência entre as proposições da RSB e o Projeto Ético Político (PEP) do Serviço Social (BRAVO, 2006). É também notável a expansão da produção de dissertações, teses, relatórios de pesquisas; a apresentação de trabalhos nos congressos da área (MATOS, 2000); bem como a publicação de livros e artigos abrangendo temáticas relacionadas à saúde e serviço social. Têm sido realizados eventos temáticos em níveis local, estadual e nacional, inclusive o "Seminário Nacional Serviço e Saúde" (2008), organizado pelo CFESS.

Vale situar também que, nos últimos decênios, vem acontecendo, de forma mais expressiva, a inserção do Serviço Social nos programas de indução do MS para formação de profissionais com perfil para atuar no SUS, a exemplo das Residências Multiprofissionais (RM), do Programa Nacional de Reorientação da Formação Profissional em Saúde (Pró-Saúde), do Programa de Educação pelo Trabalho para a Saúde (PET-Saúde) e do Projeto Estágios e Vivências na realidade do SUS (Ver-SUS) (KRUGER, 2010).

Outro importante marco para o Serviço Social na saúde foi a elaboração dos "Parâmetros para a atuação de assistentes sociais na política de saúde" (CFESS, 2010, p.9), que "(...) tem como finalidade referenciar a intervenção dos profissionais de Serviço Social na área da saúde".

No que se refere à PS/NPS, como indicam Vasconcelos e Schmaller (2013), o cenário atual tem colocado diversas demandas ao Serviço Social, sejam aquelas referentes à PNPS e às demais requisições da política sanitária atual (inclusive na saúde suplementar); sejam as estratégias no âmbito dos programas mencionados voltados para a formação no SUS, nos quais a profissão vem se inserindo.

Neste cenário, a pesquisa realizada buscou analisar as tendências da PS/NPS no debate profissional, cujos resultados estão sintetizados a seguir.

Vale indicar que uma das suposições iniciais do estudo, ao analisar as configurações da PS/NPS no Serviço Social,era a ideia de que a forma de inserção dos/as profissionais nos espaços ocupacionais, geralmente nas redes de atenção secundária e terciária (locais nos quais, comumente, a discussão sobre o tema é rarefeita), influenciaria fortemente na presença e no aprofundamento do debate sobre a PS/NPS.

Constatou-se, no entanto que,ainda que num contexto de ampliação - embora limitada do espaço ocupacional na APS (inclusive com a inserção de assistentes sociais nos Núcleos de Apoio à Saúde da Família - NASF - e nas RM); da proliferação de projetos e programas de PS/ NPS que requisitam tais profissionais para sua gestão, execução e avaliação tanto na saúde pública quanto na suplementar, quando analisadas as publicações das subáreas que, em tese, seriam mais propícias para a emersão do aprofundamento das discussões sobre PS/NPS (como a APS, a Saúde do Trabalhador/a, etc.), não houve profunda diferenciação em termos do debate nos artigos relacionados às distintas redes de atenção à saúde.

Uma primeira tendência encontrada no debate profissional foi certa invisibilidade da temática na produção da área, posto que, dos artigos analisados, apenas quatro (04) artigos tinham o termo "promoção da saúde" no título. Além disso, foram esparsos os artigos que trataram da PS/NPS de forma mais densa: embora mencionada por parte considerável das/os autores/as, tais termos não são trabalhados de forma conceitual (apenas 14 dos 112 artigos analisados apresentaram certa conceituação da PS/NPS). 
Foram poucos os artigos que fizeram menção à Conferência de Ottawa ou às demais Conferências Internacionais de Promoção da Saúde. A própria PNPS foi mencionada raras vezes.

Isso fez com que a análise, embora partisse dos artigos individuais, se voltasse mais propriamente para as tendências gerais do conjunto das publicações da área. Dessa forma, tivemos que identificar quando a PS/NPS era citada no corpo do texto, em cada artigo, buscando "descortinar" não necessariamente o conceito, mas a noção ${ }^{20}$ de PS/NPS e os elementos do debate promocional que pudessem estar presentes nas discussões.

É fundamental situar também que, no estudo realizado, não foi possível distinguir uma perspectiva "puramente" da RSB sobre a PS ou somente a partir da NPS nos textos, mas concepções que, muitas vezes, se entrelaçam, se aproximam ou se distanciam.

Uma segunda tendência dos (poucos) textos analisados que se debruçam sobre a NPS é a quase inexistência de apreciação analítica sobre as estratégias e os princípios da NPS. Nesse sentido, conceitos/princípios como equidade, empowerment, estilo de vida saudável, entre outros, comumente não são questionados em seu significado político no cenário atual. Assim, os elementos centrais da NPS são mencionados, ainda que não discutidos/conceituados.

Aqui é importante registrar que a polissemia do discurso promocional dificulta sua leitura crítica, especialmente por sua aparência de concatenação ao ideário do SUS, posição largamente divulgada pelo MS (VASCONCELOS, 2013). Além disso, no âmbito da produção da Saúde Coletiva, por vezes, encontramos um discurso acrítico sobre a NPS, posição que também tem sido, com certa medida, incorporada pelos profissionais de Serviço Social (VASCONCELOS, 2013). Nesta direção, ficou evidente, nos artigos pesquisados, uma reprodução acrítica e supervalorizada do discurso promocional, sem buscar desvelar as contradições que lhe atravessam.

Uma terceira tendência do debate profissional no tocante à PS/NPS, nos textos que a ela se remetem, é a presença da perspectiva da Vigilância da Saúde (VISAU). Esta

\footnotetext{
${ }^{20}$ Seguimos aqui a indicação presente no texto de Minayo, Hartz e Buss (2000): noção significaria um nível mais elementar de conhecimento; conceito implica uma maior elaboração analítica.
}

(...) articula os vários níveis de prevenção, enfatizando o desenvolvimento de 'políticas públicas saudáveis' e de 'ações sociais organizadas', em defesa da saúde e das melhorias de condições de vida. Fiel à ideia de 'integração' presente na proposta original da HND [História Natural da Doença], a Vigilância da Saúde trataria de articular o 'enfoque populacional' (promoção) com o 'enfoque de risco' (prevenção) e o enfoque clínico (assistência), constituindo-se, de fato, em uma estratégia de organização de um conjunto heterogêneo de políticas e práticas que assumiriam configurações específicas de acordo com a situação de saúde da(s) população(ões) em cada país, estado ou municípios (territórios) (TEIXEIRA, 2001, p.90).

Sobre a presença dessa tendência no debate do Serviço Social, é relevante mencionar algumas das críticas de Carvalho (2005) à VISAU à ênfase desta na epidemiologia e no planejamento na determinação das necessidades de saúde e a pouca atenção à clínica e à demanda espontânea, acabando por dicotomizar saúde pública e clínica. A partir das análises do autor citado, pode-se depreender também certa herança preventivista na VISAU e, portanto, nos textos analisados na pesquisa.

Uma quarta tendência do debate do Serviço Social em relação à PS/NPS se refere ao uso indiscriminado dos termos PS, prevenção e Educação em Saúde, bem como a disseminação de propostas voltadas predominantemente para estas duas últimas, conforme Vasconcelos (2013). Ainda que ultrapasse o escopo desse artigo um exame alongado desse debate, cumpre fazer algumas sumárias considerações sobre tais propostas.

A pesquisa revelou que, em diversos dos textos analisados, os termos PS, prevenção e Educação em Saúde (ES) são usados como sinônimos, geralmente considerados como "ações". Não obstante, cada um deles está associado a determinado arcabouço teórico-político, que, possivelmente, não vem sendo discutido de forma aprofundada em nossa profissão. Além disso, ressalta-se que as propostas em torno da prevenção da saúde, conforme explica Buss (2002), estão mais associadas a questões da clínica e da medicina preventiva (influenciada por Leavell e Clark, conforme discutirmos): como evitar, curar, mitigar. Seus focos são a 
doença e as estratégias para enfrentá-la através dos impactos nos fatores mais próximos que a desencadeiam; seu foco de responsabilidade e unidade de análise é o indivíduo e seus aspectos biológicos (WESTPHAL, 2006). Já a PS, estaria mais voltada para a produção da saúde, para os determinantes sociais da saúde, de acordo com Buss (2000).

Assim sendo, a prevenção, embora seja um dos componentes fundamentais para a integralidade da atenção à saúde, não toma como fundamento o conceito ampliado em saúde, mas busca evitar ou mitigar o adoecimento, referencial do qual a RSB requisita a ultrapassagem.

Como discutem Vasconcelos e Schmaller (2014), a Educação em Saúde constitui um terreno de disputas ideopolíticas, no qual várias concepções sobre a sociedade, a saúde e a educação estão em confronto. Portanto, tem-se que considerar que há diversas perspectivas no interior desse debate, com diversas gradações, indo desde vertentes higienistas, que se voltam para os indivíduos e a modificação de seus hábitos e costumes;ao enfoque individualizante e biologicista da relação saúde-doença, no qual a atividade educativa é percebida como transmissão de informações e habilidades (SILVEIRA; SILVA, 2006); até a perspectiva da Educação Popular em Saúde, que, segundo as autoras citadas, apreende o caráter político das ações educativas e realiza uma análise da realidade social, considerando os "determinantes do processo saúde-doença e instrumentalizando a ação organizada da população para a luta em torno da solução dos problemas existentes ${ }^{21 " .}$.

Cumpre situar que, de acordo com Kickbusch (1996, p.17), a NPS aparece como uma crítica ao preventivismo, mas também à $E S$, já que aquela emergiu a partir do momento em educadores sanitários perceberam que "(...) a educação para a saúde unicamente poderia desenvolver todas suas capacidades apoiando-se em medidas estruturais (legais, ambientais, normativas, etc.)". Neste contexto, a NPS é tida

\footnotetext{
21 É pertinente esclarecer que é nesta direção que a ES vem sendo tratada no Serviço Social: na perspectiva do Projeto Ético-Político, refere-se não apenas às atividades educativas, mas ao trabalho de politização, de formação política, de busca da construção da consciência sanitária, enfim, de uma contra-hegemonia. Neste sentido, as ações educativas são consideradas, nos Parâmetros para atuação das/os assistentes sociais na saúde, como um dos objetivos centrais do trabalho profissional na área.
}

como estratégia mais ampla que a ES, por partir de um enfoque mais amplo, por colocar em destaque os DSS, estando conectada aos aportes advindos de Ottawa.

Além do uso dos termos sem aprofundamento conceitual, na pesquisa empreendida, alguns dos textos analisados foi constatada certadefesa da prevenção ou da ES, colocando tais estratégias como basilares para modificação do modelo de atenção, assumindo-se a defesa de movimentos que já foram criticados desde o surgimento da Saúde Coletiva ${ }^{22}$, aparentemente desconhecendo tais considerações e também as discussões levantadas pela NPS.

A terceira tendência revelada na pesquisa se refere à compreensão da PS a partir do aporte da RSB dos anos 1980, ou seja, da concepção ampliada de saúde bem como da proposta de novo modelo de atenção dela resultante que ultrapasse os limites da prevenção. Essa perspectiva está associada à discussão da determinação social da saúde, à integralidade, à intersetorialidade, à descentralização, enfim, aos princípios do SUS. Vale salientar, porém, que nos textos analisados o debate sobre a PS/ NPS não está aprofundado.

Diante de tal cenário, constata-se que, apesar da necessidade de uma análise crítica em torno das proposições da NPS, o tratamento teórico-político da PS/NPS é embrionário no debate profissional.Ao mesmo tempo, é pertinente sinalizar que essa incipiência não diz respeito apenas ao campo conceitual, mas possuiclaras implicações para a tessitura do trabalho profissional.

É pertinente ainda destacar que essa incipiência não se restringe ao Serviço Social: como é um debate relativamente recente, bastante complexo e em torno do qual vem se fazendo uma associação à RSB, algumas profissões da área da saúde, em certa medida, embora estejam produzindo acerca do tema, geralmente não o fazem de uma perspectiva crítica.

\footnotetext{
${ }^{22}$ O livro "O dilema preventivista", de Arouca (2003), escrito em 1973 e considerado um dos marcos fundantes da Saúde Coletiva brasileira, já trazia à tona as fragilidades de propostas como as da Medicina Preventivista, que se pautam na mudança de comportamento dos profissionais, bem como em sua formação acadêmica, por não considerarem efetivamente a determinação social da saúde.
} 


\section{Considerações Finais}

Conforme discutido no artigo, a emersão da NPS coloca importantes elementos de questionamentos ao modelo biomédico, trazendo à tona discussões como o direito à saúde, as iniquidades em saúde, a intersetorialidade, os determinantes sociais, a concepção holística de saúde, etc.

No entanto, o ideário promocional pode encobrir uma abordagem funcionalista e conservadora que favorece a manutenção da ordem social; pode culpabilizar indivíduos, desconsiderando suas condições de vida e trabalho, determinadas pela forma de organização da sociedade capitalista, bem como exercendo um papel repressor e subaltenizante sobre os mesmos; pode reforçar a mercantilização da saúde, estando muitas vezes associada à indústria do bem-estar e a uma estética cultural individualista e "saudável".

No Brasil, embora a PS/NPS não tenha tido um tratamento aprofundado nas produções iniciais da Saúde Coletiva, ocupava um lugar polêmico nas discussões desta, havendo desde posturas que a incorporam acriticamente, passando por algumas redefinições que a inseriam nas discussões da RSB, até aquelas que se recusam a realizar seu debate em virtude de sua associação com a responsabilização individual pelo estilo de vida. Não obstante, subentendemos a existência de um diálogo velado entre os dois movimentos, embora a RSB, nos anos 1980, tenha assumido, a partir do referencial marxista, uma posição bem mais radical do que o debate internacional. É importante registrar, contudo, que, a partir dos anos 1990, as proposições da NPS se imiscuíram ao debate do SUS, penetrando de tal forma o delineamento da política de saúde que impregna a legislação nacional e coloca variadas questões para o trabalho na área.

Apesar de sua aparência progressista, a relevância de várias de suas propostas para a saúde pública coetânea, bem como sua suposta concatenação com o ideário da Reforma Sanitária Brasileira (RSB), a NPS é permeada de tensões políticas, filosóficas e teóricas, o que requer um esforço analítico no sentido de desvelar as contradições e polêmicas que a envolvem, bem como de analisar os traços do movimento internacional, assim como sua relação com a RSB.
Não obstante as diversificadas críticas à NPS aqui apenas sinalizadas, considera-se que o debate e as ações em torno da promoção da saúde - se fundados nas proposições daRSB -, podem contribuir o fortalecimento do SUS. Em outras palavras, o debate e as propostas em torno PS podem, inclusive, contribuir para a retomada das teses centrais da RSB nos anos 1980, em especial quanto à determinação social da saúde.

Quanto ao debate sobre o tema no Serviço Social, averiguamos que, apesar das referências à PS ou à NPS constantes na legislação sanitária e na literatura da área, bem como a remissão a noções/conceitos variados, em linhas gerais, esse tema não tem sido analisado/problematizado na produção científica de nossa área, lacuna, porém, também existente nas várias profissões sanitárias.

Vale registrar que os resultados da pesquisa aqui apresentados não trazem a totalidade da análise investigativa, dado os limites de espaços desse texto, por conseguinte, não esgotam a riqueza do debate no universo estudado e certamente requerem estudos mais aprofundados.

É fundamental, para o amadurecimento do debate sobre o tema no Serviço Social, que os/as assistentes sociais diferenciem conceitualmente a Promoção da Saúde - que tem sua base teórica na defesa da Reforma Sanitária Brasileira, nos princípios do SUS, da democracia, da participação social, do controle social, da intersetorialidade e da interdisciplinaridade - dos conceitos-chaves que dão sustentabilidade à Nova Promoção da Saúde.

Além disso, avalia-se, por um lado, há uma premente necessidade de superação de certo movimento de "negação" (consciente ou não) da discussão sobre a PS/NPS na profissão, através da incorporação ao tema de uma referência histórico-crítica, conhecendo melhor seus princípios e diretrizes, esmiuçando seu significado, apreendendo suas contradições, denunciando as distorções de alguns enunciados, enfim, transformando tão polêmico debate em objeto de estudo e reflexão de estudiosos/as e profissionais da área. Por outro lado, diante da relevância da temática para a política sanitária nacional, bem como para as demandas colocadas ao Serviço Social, este é um debate que precisa ser travado pela categoria, principalmente pelas 
contribuições que as proposições relacionadas à PS podem trazer para a profissão, se este for associado ao ideário da RSB dos anos 1980.

\section{Referências}

BRAVO, M. I. S. Política de Saúde no Brasil. In: MOTA, A.E. et al (orgs). Serviço Social e Saúde: formação e trabalho profissional. São Paulo: Cortez, 2006.

AGÊNCIA NACIONAL DE SAÚDE SUPLEMENTAR. Brasil. Nota Técnica- RN Promoção da Saúde e Prevenção de Riscos e Doenças. Rio de Janeiro: Agosto de 2011.

AROUCA, S. O dilema preventivista: contribuição para a compreensão e crítica da medicina preventiva. São Paulo: Ed. UNESP; Rio de Janeiro: Fiocruz, 2003.

BARDIN, Laurence. Análise de Conteúdo. Tradução de Luis Antero Reto e Augusto Pinheiro. São Paulo: Livraria Martins Fontes, 1977.

BRASIL. Ministério da Saúde. Secretaria de Vigilância em Saúde. Departamento de Análise de Situação de Saúde. Plano de ações estratégicas para o enfrentamento das doenças crônicas não transmissíveis (DCNT) no Brasil 2011-2022. Brasília: Ministério da Saúde, 2011b.

Secretaria de Assistência Social/ Departamento de Atenção Básica. Academia da Saúde. [s.d.]Disponível em: <http://portal.saude. gov.br/portal/saude/profissional/visualizar_texto. cfm?idtxt=37078>. Acesso em 26 Dez. 2011 ${ }^{a}$.

. Política Nacional de Promoção da Saúde. Brasília: 2006.

As Cartas da Promoção da Saúde. Brasília: Ministério da Saúde, 2002. (Série B. Textos Básicos em Saúde). 2002; 2(6):50-63. Disponivel em <http://bvsms.saude.gov.br/bvs/produtos/is_0103/ IS23\%281\%29021.pdf>.2009.

BRAVO, M. I. S.; CORREIA, M.V. Desafios do controle social na atualidade. Serviço Social e Sociedade, São Paulo, no.109 , Jan./Mar. 2012.

BUSS, PM. Promoção da Saúde da Família. Revista Brasileira de Saúde da Família,

; CARVALHO, A. I. Desenvolvimento da promoção da saúde no Brasil nos últimos vinte anos (1988-2008). Ciência \& Saúde Coletiva, v.14, n.6, p., 2305-2316, 2009.

CAMARGO JR., K.R. As Armadilhas da Concepção Positiva de Saúde. PHYSIS: Rev. Saúde Coletiva,
Rio de Janeiro, v.76, n.1, p. 63-76, 2007.

CAMPOS, G. W. S. Prefácio. In: CARVALHO, S. R. Saúde Coletiva e promoção da saúde: sujeito e mudança. São Paulo: Hucitec; Washington (DC):OPAS, 2005.

. Reflexões temáticas sobre equidade e saúde: o caso do SUS. Saúde soc. [online]. 2006b, vol.15, n.2, pp. 23-33.

Prefácio. In: CASTRO, A.; MAIO, M. (orgs.). SUS: ressignificando a promoção da saúde. São Paulo: Hucitec; Washington (DC): OPAS, 2006a.

CARVALHO, S. R. Saúde Coletiva e promoção da saúde: sujeito e mudança. São Paulo: Hucitec; Washington (DC):OPAS, 2005.

As contradições da promoção à saúde em relação à produção de sujeitos e a mudança social. Ciência \& Saúde Coletiva. [online]: v.9.n.3. p. 669678, 2004.

CASTRO, A.; MAIO, M. (orgs.). SUS: ressignificando a promoção da saúde. São Paulo: Hucitec; Washington (DC): OPAS, 2006.

CENTRO BRASILEIRO DE ESTUDOS DE SAÚDE. Proposições sobre Determinantes Sociais elaboradas pela diretoria do CEBES para o $1^{\circ}$ Simpósio de Políticas e Saúde (UFF). In: SIMPÓSIO DE POLÍTICAS E SAÚDE, 1., 2009, Rio de Janeiro. Rio de Janeiro: CEBES, 2009. p. 1 - 9. Disponível em: <http://www.cebes.org.br/media/File/ DETERMINANTES SOCIAIS3.pdf>. Acesso em: 15 nov. 2010.

CHAPELA, M.D.C.; GARCìA, A.C. Promoción de la salud y poder: reformulaciones desde el cuerpo-territorio y la exigibilidade de derechos. D.R. Universidad Autónoma Metropolitana: México, 2010.

CONSELHO FEDERAL DE SERVIÇO SOCIAL (Brasília). Parâmetros para a Atuação de Assistentes Sociais na Saúde. Brasília: CFESS, 2010 (Série Trabalho e Projeto Profissional nas Políticas Sociais).

COORDENAÇÃO DE APERFEIÇOAMENTO DE PESSOAL DE NÍVEL SUPERIOR - CAPES. Comissão de Avaliação da Área de Serviço Social. Relatório de avaliação. Disponível em <http://www.capes.gov.br/ avaliacao/qualis>. Acesso em outubro/2012.

CRUZ, D.K.A. Da promoção à prevenção: o processo de formulação da Política Nacional de Promoção da Saúde no período de 2003 a 2006. 2010. Dissertação (Mestrado Profissional em Saúde Pública) - Centro

144 Emancipação, Ponta Grossa, 14(1): 129-146, 2014. Disponível em <http://www.revistas2.uepg.br/index.php/emancipacao> 
de Pesquisa Aggeu Magalhães, Fundação Oswaldo Cruz, Recife, 2010.

CZERESNIA, D. Conceito de saúde e a diferença entre prevenção e promoção. In: _.; FREITAS, C. M. (orgs). Promoção da saúde: conceitos, reflexões, tendências. Rio de Janeiro, Fiocruz, 2003.

DEBERT, G.G. A reinvenção da velhice: socialização e processos de reprivatização do envelhecimento. São Paulo:EDUSP;FAPESP,1999.

DRUCK, G.; FILGUEIRA, L. Política social focalizada e ajuste fiscal: as duas faces do governo Lula. Katálisys. Florianópolis, jan-jun. v. 10, n. 1, 2007.

FARIA, E. Dicionário escolar Latino-Português. Companhia Nacional de educação. Ministério de Educação e Cultura. 4 ed. Rio de Janeiro, 1967.

FERREIRA, J. R.; BUSS, P. M. Atenção primária e promoção da saúde. In: BRASIL. Ministério da Saúde. Secretaria de Políticas de Saúde. As Cartas da Promoção da Saúde. Brasília: Ministério da Saúde, 2002. (Série B. Textos Básicos em Saúde).

FEUERWERKER, L. Modelos tecnoassistenciais, gestão e organização do trabalho em saúde: nada é indiferente no processo de luta para a consolidação do SUS. Temporalis: Revista da Associação Brasileira de Ensino e Pesquisa em Serviço Social. São Luiz, n. v.9, n.13, 2007.

FRANCO, T.B. et al. Reestruturação Produtiva da Saúde Suplementar no Brasil: Programas de Promoção e Prevenção. XXI Congresso da Associação Latina de Análise dos Sistemas de Saúde. Cidade do México, set. 2010. Disponível em <http://www.professores.uff.br/tuliofranco/textos/ calass-2010-reestruturacaoprodutiva-na-saudesuplementar.pdf>Acesso em 16/02/2012.

CHAPELA, M.D.C; GARCIA, A.C. Introducción. In: Promoción de la salud y poder: reformulaciones desde el cuerpo-territorio y la exigibilidade de derechos. D.R. Universidad Autónoma Metropolitana: México, 2010.

KRÜGER, T. R. Serviço Social e Saúde: espaços de atuação a partir do SUS. Revista ServiçoSocial \& Saúde. UNICAMP Campinas, v. IX, n. 10, Dez. 2010.

LALONDE, M. El concepto de "campo de la salud": una perspectiva canadiense. In.: ORGANIZACIÓN Panamericana de la Salud. Promoción de la salud: una antología. Washington (DC): OPS; 1996.

LEAVELL; H.R; CLARK, E.G. Níveis de aplicação da Medicina Preventiva. In: Medicina Preventiva.
São Paulo: Ed. McGraw-Hill, 1977.

LIMA, T.C.S.; MIOTO, R.C.T. Procedimentos metodológicos na construção do conhecimento científico: a pesquisa bibliográfica. Rev. Katálysis [online]. 2007, vol.10, n.spe, pp. 37-45.

MATOS, M. C. O debate do Serviço Social na Saúde na década de 90: sua relação com o projeto ético-político profissional e com o projeto da reforma sanitária. Dissertação de Mestrado (Serviço Social). Rio de Janeiro: PPGSS/UFRJ, 2000.

MENDES, E. V. Uma agenda para a saúde. São Paulo: HUCITEC, 1996.

MINAYO, M. C.S.; HARTZ, Z,M.A.; BUSS, P.M. Qualidade de vida e saúde: um debate necessário. Ciência \& Saúde Coletiva, v.5, n. 1, 2000. p.7-18.

OMS (ORGANIZAÇÃO MUNDIAL DE SAÚDE). "Estratégia Global em Alimentação Saudável, Atividade Física e Saúde". $57^{\text {a }}$ Assembleia Mundial de Saúde. 22 de maio de 2004. Tradução não oficial realizada pela CGPAN/MS.

European Working Group on Health Promotion Evaluation. Health promotion evaluation: recommendations to policy-makers.Copenhage, 1998. Disponível em <http://www.dors.it/ alleg/0400/1998\%20Euro\%20WHO\%20HP\%20 Evaluation\%20recommendations\%20to\%20policymakers.pdf>. Acesso em 10 Set.2012.

Atención Primaria de Salud.Informe de la Conferencia Internacional sobre Atención Primaria de Salud, Alma-Ata, URSS. Ginebra: 1978.

PAIM, J. Desafios para a saúde coletiva no século XXI. Salvador: EDFBA, 2006.

PASCHE, D. F.; HENNINGTON, E. A. O Sistema Único de Saúde e a Promoção da Saúde. In: CASTRO, A.; MALO, M. (orgs.). SUS: ressignificando a promoção da saúde. São Paulo: Hucitec; Washington (DC): OPAS, 2006.

PEREIRA, P. A. P. Política Social: temas e questões. 2 ed. São Paulo: Cortez, 2009.

RESTREPO, H. E. Conceptos y definiciones. In: .; MÀLAGA, H. Promoción de la salud: cómo construir vida saludable. Bogotá: Editorial Medica PanamericanaLtada, 2001.

SENNA, M. C. M. Equidade e política de saúde: algumas reflexões sobre o Programa Saúde da Família. Cad. Saúde Pública, Rio de Janeiro: n.18 (Suplemento), p.203-211, 2002. Suplemento. 
SILVEIRA, S.A.S.; SILVA, K. M. P. A prática do(a) assistente social no âmbito da educação em saúde no Programa Saúde da Família de Campina Grande/PB. 2006. Relatório de Pesquisa de Iniciação Científica. UEPB, Campina Grande.

SOARES, R. C. A contrarreforma na política de saúde e o SUS hoje: impactos e demandas ao Serviço Social. 2010. 210 f.Tese (Doutorado). Programa de Pós-Graduação em Serviço Social. Departamento de Serviço Social, Universidade Federal de Pernambuco, Recife, 2010. Cap. 3.

Contrarreforma na política de saúde e prática profissional do Serviço Socialnos anos 2000. MOTA, A.E. (org.). As ideologias da contrarreforma e o Serviço Social.Recife: EDUFPE, $2010 \mathrm{~b}$.

STOTZ, E. N; ARAUJO, J. W. G. Promoção da saúde e cultura política: a reconstrução do consenso. Saúde soc.[online], vol.13, n.2, pp. 5-19, 2004.

TAMBELLINI, A.T; SCHUTZ, G.E. Contribuição para o debate do CEBES sobre a Determinação Social da Saúde: repensando processos sociais, determinações e determinantes da saúde. Saúde em Debate. Rio de Janeiro, v.33, n.83, set-dez. 2009.

. A Mudança do modelo de atenção à saúde no SUS: desatando nós, criando laços. Saúde em Debate, Rio de Janeiro, v. 27, n. 65, 2003.

Promoção da Saúde e SUS: um diálogo pertinente. In: CASTRO, A.; MALO, M.(orgs.). SUS: ressignificando a promoção da saúde. São Paulo: Hucitec; Washington (DC): OPAS, 2006.

. Prevenção, promoção e vigilância da saúde. In: _. O futuro da prevenção. Salvador: Casa da Qualidade, 2001.

TEIXEIRA, S. F. Retomar o debate sobre a reforma sanitária para avançar o Sistema Único de Saúde (SUS). ERA. São Paulo, v. 49, n.4, out-dez. 2009.

TEIXEIRA, S. F. Reflexões teóricas sobre democracia e Reforma Sanitária. In.: (org.). Reforma Sanitária: em busca de uma teoria. São Paulo: Cortez; Rio de Janeiro: ABRASCO, 1989.

TERRIS, M. Conceptos de la promoción de la salud: dualidade de la teoría de la salud pública. In: ORGANIZACIÓN Panamericana de la Salud. Promoción de la salud: uma antología. Washington (DC): OPS; 1996.

VASCONCELOS, Kathleen Elane Leal. Promoção da Saúde e Serviço Social: uma análise do debate profissional. 2013. 348 f. Tese (Doutorado)
- Programa de Pós-Graduação em Serviço Social, Departamento de Serviço Social, Universidade Federal de Pernambuco, Recife, 2014.

.; SCHMALLER, V. P. V. Estratégia Saúde da Família: foco da disputa entre projetos sanitários no Brasil. Sociedade em Debate, Pelotas, v.17, n.1, p. 89-118, Jan.-Jun. 2011.

; _ . O debate sobre a Nova Promoção da Saúde e a Reforma Sanitária Brasileira: convergências e dissonâncias. In: OFICINA REGIONAL DAABEPSS, 24., 2013, João Pessoa. Anais da Oficina Regional da ABEPSS. João Pessoa: ABEPSS, 2013. v. 1, 09 p.

Promoção da Saúde: polissemias conceituais e ideopolíticas. In:VASCONCELOS, K.E.L; COSTA, M.D.H.C. (orgs.) Por uma crítica da Promoção da Saúde: contradições e potencialidades no contexto do SUS. São Paulo: HUCITEC, 2014. Pp. 47-110.

VIEIRA-DA-SILVA, Ligia Maria; ALMEIDA FILHO, Naomar de. Equidade em saúde: uma análise crítica de conceitos. Cad. Saúde Pública, Rio de Janeiro, v. 25, n. 2, p.217-226, jun. 2009. Disponível em: <http://www.scielo.br/scielo.php?pid=S0102$311 X 2009001400004 \&$ script=sci_arttext>. Acesso em: 23 dez. 2013.

WESTPHAL, Márcia Faria. Promoção da saúde e a qualidade de vida. In: FERNANDEZ, J.C; MENDES, R. (orgs). Promoção da saúde e gestão local. São Paulo: Aderaldo \&Rothschild, 2007 (Série Saúde em Debate). 